\title{
Acute and chronic toxicity of six anticancer drugs on rotifers and crustaceans
}

\author{
Alfredo Parrella, Margherita Lavorgna, Emma Criscuolo, Chiara Russo, Vittorio Fiumano, Marina Isidori* \\ Dipartimento di Scienze e Tecnologie Ambientali, Biologiche e Farmaceutiche, Seconda Università di Napoli, Via Vivaldi 43, I-81100 Caserta, Italy
}

H I G H L I G H T S

- Acute and chronic toxicity of cytostatics on rotifers and crustaceans were assessed.

- Cisplatin and 5-fluorouracil had the highest chronic toxicity on all test organisms.

- This study contributes to cytostatic environmental risk evaluation.

\section{A R T I C L E I N F O}

\section{Article history:}

Received 22 August 2013

Received in revised form 25 November 2013

Accepted 6 January 2014

Available online $\mathrm{xxxx}$

\section{Keywords:}

Cytostatics

Anticancer drugs

Acute toxicity

Chronic toxicity

Rotifers

Crustacea

\begin{abstract}
A B S T R A C T
The growing use of cytostatic drugs is gaining relevance as an environmental concern. Environmental and distribution studies are increasing due to the development of accurate analytical methods, whereas ecotoxicological studies are still lacking. The aim of the present study was to investigate the acute and chronic toxicity of six cytostatics (5-fluorouracil, capecitabine, cisplatin, doxorubicin, etoposide, and imatinib) belonging to five classes of Anatomical Therapeutic Classification (ATC) on primary consumers of the aquatic chain (Daphnia magna, Ceriodaphnia dubia, Brachionus calyciflorus, and Thamnocephalus platyurus). Acute ecotoxicological effects occurred at concentrations in the order of $\mathrm{mg} \mathrm{L}^{-1}$, higher than those predicted in the environment, and the most acutely toxic drugs among those tested were cisplatin and doxorubicin for most aquatic organisms. For chronic toxicity, cisplatin and 5-fluorouracil showed the highest toxic potential in all test organisms, inducing 50\% reproduction inhibition in crustaceans at concentrations on the order of $\mu \mathrm{g} \mathrm{L}^{-1}$. Rotifers were less susceptible to these pharmaceuticals. On the basis of chronic results, the low effective concentrations suggest a potential environmental risk of cytostatics. Thus, this study could be an important starting point for establishing the real environmental impact of these substances.
\end{abstract}

(c) 2014 Elsevier Ltd. All rights reserved.

\section{Introduction}

For years the scientific community has been studying the presence and effects of pharmaceuticals in the aquatic environment, but only in the last few years, the focus of scientific concern about anticancer drugs has been growing due to their ever-increasing use (Johnson et al., 2008). Chemotherapy is growing because the incidence rates of some cancers are increasing (US National Institute of Health, www.cancer.gov) and higher doses of antineoplastic agents are being prescribed for the enhanced ability to control their side effects (Suhail et al., 2012). Additionally, treatment is moving towards the administration of a combination of more drugs (Shi et al., 2012). Furthermore, chemotherapy has been changing from in-patient to out-patient cancer treatment (Lenz et al., 2007), with higher environmental concern over the presence

\footnotetext{
* Corresponding author. Tel.: +390823 274565.

E-mail address: marina.isidori@unina2.it (M. Isidori).
}

of cytostatics not only in hospital effluents, but also in municipal wastewater treatment plant effluents at concentrations from ng to $\mu \mathrm{g} \mathrm{L}^{-1}$ as shown in Table 1 . Anticancer drugs can be excreted as parent compounds or as one or more metabolites and, once in the water, they can undergo biotic and/or abiotic transformations into different compounds that can be more persistent and more toxic than the parent compounds (Mompelat et al., 2009).

The concern is that cytostatic drugs interfere with the structure and functions of DNA and affect not only target cells, but also nontumoral cells. Generally, these drugs are present at low concentrations in the environment, concentrations below those of other pharmaceutical classes. However, each living organism may potentially be affected by their peculiar molecular mode of action and by the fact that they are expected to exert effects at very low concentrations. The development of accurate analytical methods has allowed the detection of the most abundant anticancer agents in aquatic systems, such as 5-fluorouracil (5-FU), ifosfamide, and cyclophosphamide (Kovalova et al., 2009; Kosjek et al., 2013; 
Table 1

Occurrence and predicted environmental concentration, refined by excretion rates, of cytostatic pharmaceuticals in aquatic systems.

\begin{tabular}{|c|c|c|c|c|}
\hline Cytostatic & Matrix & Concentration detected & Refined PEC & Ref. \\
\hline \multirow[t]{10}{*}{ 5-FU } & Hospital effluent & $<5.0-27 \mathrm{ng} \mathrm{L}^{-1}$ & - & Kovalova et al. (2009) \\
\hline & Hospital effluent & $20-122 \mu \mathrm{g} \mathrm{L}^{-1}$ & - & Mahnik et al. (2004) \\
\hline & Hospital effluent & $<8.6-124 \mu \mathrm{g} \mathrm{L}^{-1}$ & - & Mahnik et al. (2007) \\
\hline & Hospital wastewater & - & $2.03 \mu \mathrm{g} \mathrm{L}^{-1}$ & Hartmann et al. (1998) \\
\hline & Municipal wastewater & - & $<23 \mathrm{ng} \mathrm{L}^{-1}$ & Tauxe-Wuersch et al. (2006) \\
\hline & Surface water & - & 2.65 ng L-1 & Straub (2009) \\
\hline & Wastewater influent & - & $44.8 \mathrm{ng} \mathrm{L}^{-1}$ & Straub (2009) \\
\hline & Surface water & - & $7.91 \mathrm{ng} \mathrm{L}^{-1}$ & Besse et al., 2012 \\
\hline & Hospital wastewater & $35-92 \mathrm{ng} \mathrm{L}^{-1}$ & - & Kosjek et al. (2013) \\
\hline & Municipal wastewater & $4.7-14 \mathrm{ng} \mathrm{L}^{-1}$ & - & Kosjek et al. (2013) \\
\hline \multirow[t]{2}{*}{ CAP } & Surface water & - & 3.52 ng L-1 & Besse et al. (2012) \\
\hline & Wastewater influent & $8.2-27 \mathrm{ng} \mathrm{L}^{-1}$ & - & Negreira et al. (2013) \\
\hline \multirow[t]{2}{*}{ CisPt as Pt compound } & Hospital influent & $3-250 \mu \mathrm{g} \mathrm{L}^{-1}$ & - & Lenz et al. (2007) \\
\hline & Hospital effluent & $2-150 \mu \mathrm{g} \mathrm{L}^{-1}$ & - & Lenz et al. (2007) \\
\hline \multirow[t]{5}{*}{ DOX } & Hospital effluent & $0.1-0.5 \mu \mathrm{g} \mathrm{L}^{-1}$ & - & Mahnik et al. (2006) \\
\hline & Hospital effluent & $<10 \mathrm{ng} \mathrm{L}^{-1}$ & - & Yin et al. (2010) \\
\hline & Hospital effluent & $<0.26-1.35 \mu \mathrm{g} \mathrm{L}-1$ & - & Mahnik et al. (2007) \\
\hline & Surface water & - & $0.19 \mathrm{ng} \mathrm{L}^{-1}$ & Besse et al. (2012) \\
\hline & Wastewater influent & $4.5 \mathrm{ng} \mathrm{L}^{-1}$ & - & Martin et al. (2011) \\
\hline \multirow[t]{5}{*}{ ET } & Hospital effluent & $6-380 \operatorname{ng~L~}^{-1}$ & - & Yin et al. (2010) \\
\hline & Hospital effluent & $110-600 \mathrm{ng} \mathrm{L}^{-1}$ & - & Catastini et al. (2008) \\
\hline & Surface water & - & $0.87 \mathrm{ng} \mathrm{L}^{-1}$ & Besse et al. (2012) \\
\hline & Wastewater effluent & $3.4 \mathrm{ng} \mathrm{L}^{-1}$ & - & Martin et al. (2011) \\
\hline & Wastewater influent & $15 \mathrm{ng} \mathrm{L}^{-1}$ & - & Martin et al. (2011) \\
\hline IM & Surface water & - & $4.99 \mathrm{ng} \mathrm{L}^{-1}$ & Besse et al. (2012) \\
\hline
\end{tabular}

5-Fluorouracil (5- FU), capecitabine (CAP), cisplatin (CisPt), doxorubicin (DOX), etoposide (ET) and imatinib (IM).

Negreira et al., 2013), those occurring at lower concentrations, such as doxorubicin (DOX), vincristine, and etoposide (ET), and new compounds, such as imatinib mesylate (IM), temozolomide, and capecitabine (CAP) (Besse et al., 2012; Negreira et al., 2013).

Though the number of studies on the detection of anticancer agents in the environment is increasing, studies on the ecotoxicological effects of these compounds and the associated risk to human health due to their presence in the aquatic environment are lacking (Xie, 2012). Therefore, the aim of the present study was to investigate the toxicity of six cytostatics belonging to the five classes of the World Health Organization (WHO) Anatomical Therapeutic Classification (ATC) scheme, on different organisms in the aquatic chain.

5-FU and CAP are pyrimidine analogues characterized as antimetabolites. This class of drugs inhibits DNA polymerase and induces cell cycle arrest and apoptosis. CAP is the pro-drug of fluorouracil and rapidly metabolizes to the active 5-FU (Straub, 2009). Cisplatin (CisPt) is an inorganic platinum agent belonging to the class of platinum-derived drugs. These platinum compounds form highly reactive platinum complexes that bind to nucleophilic groups in DNA, inducing DNA cross-links and DNA-protein cross-links, resulting in apoptosis and inhibition of cell growth (Kartalou and Essigmann, 2001). CisPt has been classified by the International Agency for Research on Cancer (IARC) as a presumable carcinogen in humans (group 2A), whereas ET, a topoisomerase II inhibitor belonging to the class of mitotic inhibitors, has already been classified by IARC as a carcinogen in humans (group 1). DOX is characterized as a cytotoxic antibiotic (anthracycline class). Anthracyclines interact with DNA, intercalating between two base pairs to block DNA replication and prevent DNA relegation by stabilizing topoisomerase II (Xie, 2012). Other mechanisms of action are controversial despite the drugs' extensive clinical utilization (Minotti et al., 2004). Imatinib mesylate is a selective tyrosine kinase inhibitor belonging to the new class of kinase inhibitors. Tyrosine kinases play a critical role in the modulation of growth factor signalling. Activated forms of these enzymes can cause increased tumor cell proliferation and growth, induce antiapoptotic effects, and promote angiogenesis and metastasis (Blume-Jensen and Hunter, 2001).
In order to evaluate the potential ecotoxicological effects of the six cytostatics described above, acute and chronic toxicity assays were carried out on primary consumers of the freshwater aquatic chain. Our results could be utilized for the evaluation of the potential environmental risk from these compounds as only limited data currently exists. The stability of compounds in stock solutions and test solutions was also investigated in order to establish possible differences between nominal and actual concentrations.

\section{Materials and methods}

\subsection{Test compounds}

5-FU (CAS: 51-21-8), CisPt (CAS: 15663-27-1), ET (CAS: $33419-$ 42-0), and DOX (CAS: 25316-40-9) were supplied by SigmaAldrich (Milano, Italy). CAP (CAS: 154361-50-9) and IM (CAS: 220127-57-1) were supplied by Santa Cruz Biotechnology (Santa Cruz, CA, USA).

\subsection{Chemical analysis}

For 5-FU, CAP, ET, and IM, analytical HPLC was carried out using a Varian 1200 Series HPLC system equipped with a Varian 1200 G1311A quaternary pump, Varian 1200 G1329A auto sampler, and Varian 1200 G1314B UV-Vis detector. Chromatographic analyses were performed on a LUNA RP-18 column $(5 \mu \mathrm{m}$, $250 \times 4.6 \mathrm{~mm}$ i.d., Phenomenex) assembled with a pre-column SecurityGuard ${ }^{\mathrm{TM}}$ HPLC system consisting of a Max RP guard cartridge $(4.0 \times 2.0 \mathrm{~mm}$, Phenomenex $)$. An aliquot of each sample $(1 \mathrm{~mL})$ was transferred into a HPLC vial and $20 \mu \mathrm{L}$ injected. Chromatograms were integrated using Agilent Chemstation software (A6.03.05).

5-FU, CAP, ET, and IM were identified by comparing retention times with authentic standards and quantified using standard calibration curves. A total of $20 \mu \mathrm{L}$ of each standard dilution in $1: 1$ methanol:acetonitrile was used to prepare 5-point calibration curves, which were linear in the analytical ranges $\left(0.1-1000 \mathrm{mg} \mathrm{L}^{-1}\right.$ for 5-FU, 1-1000 $\mathrm{mg} \mathrm{L}^{-1}$ for CAP, $10-1000 \mathrm{mg} \mathrm{L}^{-1}$ for ET and IM). 
For 5-FU, isocratic elution in a mixture of purified water and methanol $(9: 1, v / v)$ containing $0.1 \%$ formic acid was carried out over $20 \mathrm{~min}$ at a flow rate of $0.3 \mathrm{~mL} \mathrm{~min}^{-1}$ with detection at $254 \mathrm{~nm}$ (modified from Baek et al., 2010). The 5-FU retention time was $14.6 \mathrm{~min}$. A solution of $5-\mathrm{FU}(100 \mathrm{ppm})$ in $\mathrm{D}_{2} \mathrm{O}$ was prepared, measured, and then stored under the same conditions as the stock solutions. ${ }^{1} \mathrm{H},{ }^{13} \mathrm{C}$, and ${ }^{19} \mathrm{~F}$ NMR spectra were recorded in $\mathrm{D}_{2} \mathrm{O}$ at $25^{\circ} \mathrm{C}$ on a Varian Mercury Plus 300 spectrometer equipped with 5 -mm probes. ${ }^{1} \mathrm{H},{ }^{13} \mathrm{C}$, and ${ }^{19} \mathrm{~F}$ NMR spectra were acquired with a standard pulse from the Varian library $\left({ }^{1} \mathrm{H}\right.$ NMR: $\left(\mathrm{D}_{2} \mathrm{O}\right) \delta$ in ppm, 7.26 ( $1 \mathrm{H}, \mathrm{s}, \mathrm{J}=5.4 \mathrm{~Hz}, \mathrm{H}-6)$ ).

For CAP, isocratic elution in a mixture of purified water and methanol $(1: 1, v / v)$ was carried out over $20 \mathrm{~min}$ at a flow rate of $0.7 \mathrm{~mL} \mathrm{~min}{ }^{-1}$ with detection at $280 \mathrm{~nm}$. The CAP retention time was $15.2 \mathrm{~min}$.

For ET, isocratic elution in a mixture of purified water containing $0.1 \%$ trifluoroacetic acid, methanol, and acetonitrile $(52: 45: 3, \mathrm{v} /$ $\mathrm{v} / \mathrm{v}$ ) was carried out over $20 \mathrm{~min}$ at a flow rate of $0.7 \mathrm{~mL} \mathrm{~min}^{-1}$ with detection at $229 \mathrm{~nm}$. The ET retention time was $12.2 \mathrm{~min}$.

For IM, isocratic elution in a mixture of purified water containing $0.1 \%$ formic acid and methanol $(1: 1, \mathrm{v} / \mathrm{v})$ was carried out over $12 \mathrm{~min}$ at a flow rate of $0.7 \mathrm{~mL} \mathrm{~min}{ }^{-1}$ with detection at $268 \mathrm{~nm}$. The IM retention time was $7.5 \mathrm{~min}$.

For CisPt and DOX, absorbance was measured in the range of 700-200 nm using a Cary model 1E double beam UV-Vis Spectrophotometer with a spectral resolution of $2 \mathrm{~nm}$. Repeated spectrophotometric scans (10 min intervals) of $1 \mathrm{mg} \mathrm{mL}^{-1}$ CisPt solution in fresh water were recorded at $20 \pm 2{ }^{\circ} \mathrm{C}$ for $8 \mathrm{~h}$. An aliquot of $1.5 \mathrm{~mL}$ of $50 \mathrm{mg} \mathrm{L}^{-1}$ DOX solution in fresh water was placed in a quartz cuvette and incubated at $20 \pm 2{ }^{\circ} \mathrm{C}$ with a 16 :8 light:dark cycle (500 lux). The spectrophotometric scans were recorded at fixed time points chosen to investigate light-induced degradation under test conditions $(0,1,16,24,25,40,48,49,64$, and $72 \mathrm{~h})$. The DOX concentration was measured by the absorbance at $480 \mathrm{~nm}\left(\lambda_{\max }\right.$ for DOX).

\subsection{Toxicity testing}

To evaluate the environmental effects of the six anticancer agents selected, aquatic acute and chronic toxicity tests were performed on the following primary consumers: the anostracan crustacean Thamnocephalus platyurus was used in acute tests, and the rotifer Brachionus calyciflorus and the cladoceran crustaceans Daphnia magna and Ceriodaphnia dubia were used in both acute and chronic tests. The selection of $B$. calyciflorus as a representative aquatic organism in this study was justified by its environmental abundance and role in several ecological processes in freshwater communities. T. platyurus was used due to its high sensitivity to toxicants (Tarczynska et al., 2001; Zaltauskaite and Brazaityte, 2013), D. magna and C. dubia due to their worldwide distribution in freshwater and because they are largely used in both standard acute and chronic toxicity testing.

5-FU, ET, and DOX were dissolved in dimethylsulphoxide (DMSO), stored in the dark at $4{ }^{\circ} \mathrm{C}$, further diluted in deionized water (Elix 10, Millipore, Milan, Italy) and sonicated to obtain stock solutions. The test solutions were prepared by mixing the appropriate volumes of the stock solutions and the test media. Because of the low solubility of 5-FU and ET, we utilized DMSO as solvent at the maximum concentration of $0.025 \% \mathrm{v} / \mathrm{v}$. The maximum concentration of DMSO used in DOX test solution was $0.01 \%$ while CisPt, IM, and CAP were dissolved in deionized water. While acute toxicity testing a carrier control with DMSO was performed at the concentrations utilized. The concentrations used in the chronic toxicity tests were based on results from acute tests when possible, and from previous range-finding tests. In chronic tests it was not necessary to dissolve pharmaceuticals in DMSO for the low concentrations used. The acute bioassays were conducted under static conditions, whereas the chronic bioassays were performed under semi-static conditions.

\subsection{Acute toxicity tests}

The B. calyciflorus (ASTM E1440-91) test was performed on organisms less than $2 \mathrm{~h}$ old that hatched from cysts supplied by MicroBioTest Inc. (Nazareth, Belgium). The hatching occurred 16$18 \mathrm{~h}$ before the start of the test in synthetic freshwater (moderately hard dilution water ASTM, 80-100 $\mathrm{mg} \mathrm{L}^{-1} \mathrm{CaCO}_{3}$, $\mathrm{pH} 7.5 \pm$ 0.3 ) at $25 \pm 1{ }^{\circ} \mathrm{C}$ and under continuous illumination (3000-4000 lux). Five to seven concentrations $(0.3 \mathrm{~mL}$ of test solution for each test well) of each compound were tested in six replicates with five animals.

The T. platyurus test was performed following the new standard guideline ISO 14380 (2011) over $24 \mathrm{~h}$ of exposure using secondand third-instar fairy shrimp larvae hatched from cysts. The hatching occurred 20-22 h before the assay in the same synthetic freshwater as the rotifers with the same light and temperature conditions. Tests were performed in 24 -well plates with 10 crustaceans per well $(1.0 \mathrm{~mL}$ of test solution), five to six concentrations, and three replicates per concentration.

The $C$. dubia test was performed over $24 \mathrm{~h}$ of exposure using young organisms less than $24 \mathrm{~h}$ old and following EPA-600-4-90 (applied to reference toxicant) procedures (US EPA, 1993). At least the third generation from mass cultures (starting organisms from Aquatic Research Organisms, Inc., Hampton, NH, USA) was used, as well as organisms hatched from ephippia (MicroBioTest) after $3-4 \mathrm{~d}$ of incubation under a light source of 6000 lux at $25 \pm 1{ }^{\circ} \mathrm{C}$ in synthetic ISO medium (hardness $250 \mathrm{mg} \mathrm{L}^{-1}$ expressed as $\left.\mathrm{CaCO}_{3}\right)$ in order to observe potential differences. Tests were performed in 24-well plates with 10 crustaceans per well $(1.0 \mathrm{~mL}$ of test solution), five to eight concentrations, and three replicates per concentration.

For each test considered above, plates were incubated in darkness at $25{ }^{\circ} \mathrm{C}$ for $24 \mathrm{~h}$. The test parameter was mortality, and the concentration that resulted in a $50 \%$ effect in $24 \mathrm{~h}$ was indicated as the $\mathrm{LC}_{50}$.

The acute $D$. magna Straus test was performed over $48 \mathrm{~h}$ of exposure on neonates less than $24 \mathrm{~h}$ old at $20 \pm 1{ }^{\circ} \mathrm{C}$ in the dark following the OECD 202 (2004) and ISO 6341 (1996) guidelines. As for C. dubia, experiments were performed on both organisms coming from mass cultures and ephippia. The synthetic freshwater (ISO medium) was aerated before use. Tests were performed with five daphnids per vessel ( $9 \mathrm{~mL}$ of test solution) and four replicates for each of five to six concentrations. The test endpoint was the inhibition of mobility, and the concentration found to immobilize $50 \%$ of crustaceans in $48 \mathrm{~h}$ was considered as $\mathrm{EC}_{50}$.

\subsection{Chronic toxicity tests}

The $B$. calyciflorus test was based on population growth inhibition over $48 \mathrm{~h}$ of exposure (ISO 20666, 2008) and performed on young organisms less than $2 \mathrm{~h}$ old. Cysts were hatched as previously described for the acute test. Tests were performed in 48 -well plates with one rotifer per well $(0.9 \mathrm{~mL}$ of test solution) and six replicates of each of five to seven concentrations in moderately hard dilution water (ASTM E1440-91). The organisms were fed with $0.1 \mathrm{~mL}$ of a fresh suspension of $10^{7}$ cells $/ \mathrm{mL}$ of the unicellular alga Pseudokirchneriella subcapitata. Plates were incubated in darkness at $25^{\circ} \mathrm{C}$ for $48 \mathrm{~h}$.

The inhibition reproduction tests on D. magna (OECD 211, 2008 and ISO 10706, 2000) were performed over $21 \mathrm{~d}$ of exposure on young female organisms less than $24 \mathrm{~h}$ old that were part of the third-fifth generation isolated from a healthy mass culture. The 
organisms were transferred to glass beakers (one organism in each beaker) containing $50 \mathrm{~mL}$ of sample concentrations. Crustaceans were maintained and tested in moderately fresh water (hardness $170 \mathrm{mg} \mathrm{L}^{-1}$, expressed as $\mathrm{CaCO}_{3}$; ISO 10706). All test media were exchanged three times a week (semi-static conditions). The offspring produced by each parent animal were counted and removed at renewal time starting from day 9-11 of exposure.

The inhibition reproduction tests on $C$. dubia were performed over 7 d (ISO 20665, 2008). C. dubia stock cultures were maintained in synthetic water with ISO medium (hardness $250 \mathrm{mg} \mathrm{L}^{-1}$ expressed as $\mathrm{CaCO}_{3}$ ). Females were exposed individually in beakers with $25-30 \mathrm{~mL}$ of test solution. All test media were exchanged five times per week (semi-static conditions). Daily, at the renewal time, the offspring produced by each parent animal were counted and removed starting from the fourth day of exposure.

A combination of $5 \mathrm{~g} \mathrm{~L}^{-1}$ each of yeast (Saccharomyces cerevisiae), alfalfa, and flake food (YCT), in addition to the unicellular green alga Pseudokirchneriella subcapitata $\left(10^{8}\right.$ cells $/ \mathrm{mL}$ from cultures), provided suitable nutrition for crustaceans; the organisms were fed daily with $200 \mu \mathrm{L}$ of the YCT/algae (1/1) suspension. Five to ten concentrations, ten replicates per concentration were incubated at $20 \pm 1{ }^{\circ} \mathrm{C}$ for $D$. magna and $25 \pm 1{ }^{\circ} \mathrm{C}$ for $C$. dubia, with a $16: 8 \mathrm{~h}$ light:dark cycle (500 lux). For all chronic tests, a test-medium control series (negative control) was used in addition to the test series. The reproductive output of the females exposed to the cytostatics was compared to that of the negative control to determine the reproduction inhibition concentrations $\left(\mathrm{EC}_{\mathrm{x}}\right)$.

\subsection{Quality assurance/control procedures in acute and chronic toxicity testing}

The accuracy of the acute and chronic tests was measured using $\mathrm{K}_{2} \mathrm{Cr}_{2} \mathrm{O}_{7}$ and $\mathrm{CuSO}_{4} \cdot 5 \mathrm{H}_{2} \mathrm{O}$ (Sigma-Aldrich Chemicals), respectively, in reference toxicant tests in order to verify that the $\mathrm{L}(\mathrm{E}) \mathrm{C}_{50}$ S were in the known ranges for the acute and chronic toxicities of the organisms. Control charts of organisms were filled with the intralaboratory data from several acute and chronic toxicity tests with rotifers, crustaceans, and reference toxicants in order to guarantee the precision of the tests. Temperature, hardness, dissolved oxygen, conductivity, and $\mathrm{pH}$ were checked at the beginning and at the end of each test. For each test, data was processed only if the validity criteria were satisfied according to the respective standard guidelines.

All people involved in the experiments with cytostatics were aware of the risks. Lab work was performed in compliance with current safety guidelines and the use of personal protective equipment. Furthermore, proper disposal procedures for hazardous wastes were followed.

\subsection{Data analysis}

The cytostatics were tested at least three times (three independent assays) for each organism. The results from the three respective assays were pooled and analysed using ToxRat Professional software, Ver 2.10.05 (Alsdorf, Germany) to calculate the effective percentages. Prism5 (Graphpad Inc., CA, USA) was used to estimate the concentrations giving $\mathrm{x} \%$ effect $\left(\mathrm{L}(\mathrm{E}) \mathrm{C}_{\mathrm{x}}\right)$ by non-linear regression (log agonist vs. normalized response-variable slope). The $\mathrm{L}(\mathrm{E}) \mathrm{C}_{50}$ value, corresponding to the $50 \%$ immobilization for $D$. mag$n a$ and mortality for other organisms, were the test parameters in acute tests, whereas $\mathrm{EC}_{50}, \mathrm{EC}_{20}$, and $\mathrm{EC}_{10}$ were used in chronic tests as inhibition reproduction effect concentrations. For long-term toxicity, the Lowest Observed Effect Concentration (LOEC) and the No Observed Effect Concentration (NOEC) were estimated by ANOVA and Dunnett's multiple comparison test comparing the mean number of live offspring produced per parent in each exposure concentration to the control mean.

\section{Results and discussion}

\subsection{Chemical results}

HPLC demonstrated that 5-FU, CAP, ET, and IM were stable in aqueous stock solutions when stored at $4{ }^{\circ} \mathrm{C}$ in the dark. 5 -FU was stable under storage conditions since ${ }^{1} \mathrm{H},{ }^{13} \mathrm{C}$, and ${ }^{19} \mathrm{~F}$ NMR acquired soon after dissolution and after $10 \mathrm{~d}$ were super-imposable (Fig. 1 supplementary data). The actual concentrations of these cytostatics diverged from the nominal concentrations at the start of the test by less than $10 \%$, and as such the nominal concentrations were reported as the actual concentrations. HPLC demonstrated that 5-FU, CAP, ET, and IM were also stable under test conditions in $3 \mathrm{~d}$.

Spectrophotometric analysis demonstrated that CisPt was very reactive in test media. Soon after dissolution, a decrease in the absorbance around $301 \mathrm{~nm}$ ( $\lambda_{\max }$ for CisPt) and an increase around 248 and $272 \mathrm{~nm}$ were observed until 2 h (Fig. 1), then a general increase at all three wavelengths was observed until a stable mixture was established $(8 \mathrm{~h})$. These observations were interpreted as the result of the hydrolysis and anation of CisPt in the test solution (Miller and House, 1989a; Miller and House, 1989b; Miller and House, 1990).

In agreement with previous studies (Nawara et al., 2012), the DOX concentration exponentially decreased during the light period, resulting in approximately $60 \%, 30 \%$, and $20 \%$ of the starting concentration after the first, second, and third light:dark cycle, respectively (Fig. 2).

\subsection{Acute toxicity results}

No significant differences were found between the results obtained using laboratory cultures and ephippia. Carrier controls showed no toxicity at the concentrations tested. $\mathrm{L}(\mathrm{E}) \mathrm{C}_{50}$ values for the cytostatics are reported in Table 2.D. magna and T. platyurus were more sensitive to anticancer agents than C. dubia and B. calyciflorus. Among the pharmaceuticals tested, the most toxic were CisPt and DOX for most organisms, with $\mathrm{L}(\mathrm{E}) \mathrm{C}_{50}$ values in the order of $\mathrm{mg} \mathrm{L}^{-1}$, followed by IM, 5-FU, and CAP. ET exhibited low toxicity and it was not possible to perform experiments at concentrations higher than $120 \mathrm{mg} \mathrm{L}^{-1}$ for its low solubility in the test medium. Then, its median effective concentration was possible to be calculated only for $T$. platyurus. No effect on B. calyciflorus was found for 5-FU, CAP and ET, up to 200,500 and $120 \mathrm{mg} \mathrm{L}^{-1}$, respectively, while IM was the most toxic among the compounds tested on this organism $\left(\mathrm{LC}_{50}=3.82 \mathrm{mg} \mathrm{L}^{-1}\right)$.

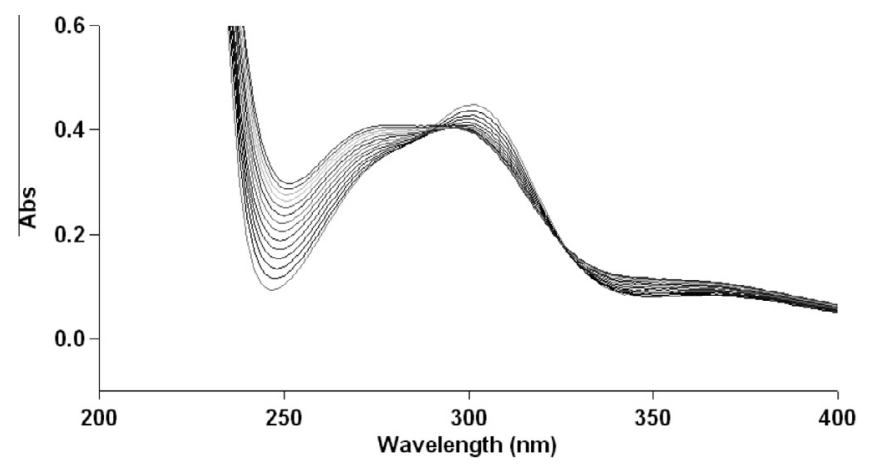

Fig. 1. Spectrophotometric scans of the hydrolysis and anation of $1 \mathrm{mg} \mathrm{mL}^{-1} \mathrm{CisPt}$ solution over $2 \mathrm{~h}$. Medium, $20 \pm 2{ }^{\circ} \mathrm{C}, 10 \mathrm{~min}$ intervals. 


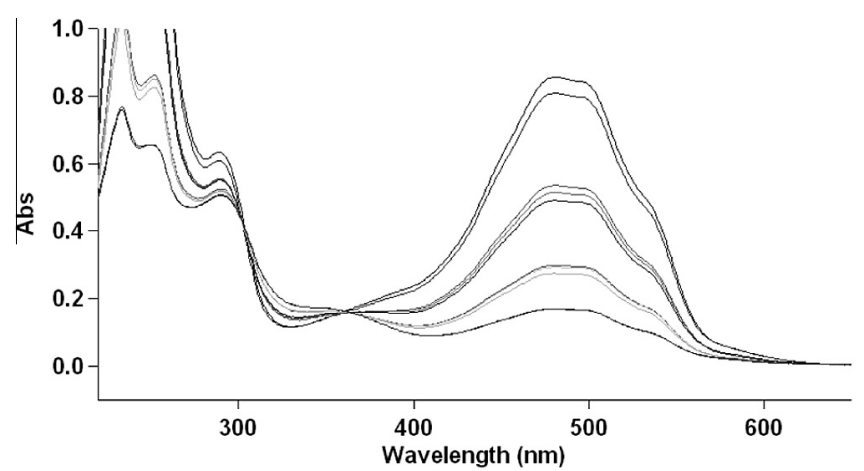

Fig. 2. Spectrophotometric scans of $50 \mathrm{mg} \mathrm{L}^{-1}$ DOX solution recorded at time points $0,1,16,24,25,40,48,49,64$, and $72 \mathrm{~h}$. Growth medium, $20 \pm 2{ }^{\circ} \mathrm{C}, 16: 8,500$ lux.

5-FU was slightly toxic to D. magna but it had the lowest $\mathrm{EC}_{50}$ value $\left(0.28 \mathrm{mg} \mathrm{L}^{-1}\right)$ with $T$. platyurus. CAP was the lowest toxic drug for all organisms, with $\mathrm{L}(\mathrm{E}) \mathrm{C}_{50}$ values two or three orders of magnitude higher than other chemicals. Furthermore, the CAP $\mathrm{EC}_{50}$ value for $D$. magna (224 $\mathrm{mg} \mathrm{L}^{-1}$ ) was one order of magnitude higher than that of its metabolite 5-FU, and the same order of magnitude difference was reported by Straub (2009).

Regarding $D$. magna, the results were in agreement with those of Zounkova et al. (2007) for 5-FU, CisPt, and DOX, but they differed for ET.

The acute toxicity of the compounds tested occurred at high concentrations, in the order of $\mathrm{mg} \mathrm{L}^{-1}$, far greater than the concentrations found in aquatic systems (Table 1). Many cytotoxic compounds have high polarity and low volatility and are not removed by wastewater treatment (Brausch et al., 2012), but their potential environmental effects remain largely unknown. 5-FU is not degraded in wastewater treatment plants and it is detectable at concentrations in the order of $\mathrm{ng} \mathrm{L}^{-1}$ (Kosjek et al., 2013). Data is scarce regarding the presence of platinum compounds, but the effluent Pt concentrations from a hospital in Vienna ranged from 2 to $150 \mu \mathrm{g} \mathrm{L}^{-1}$ (Lenz et al., 2007). DOX was also found in hospital effluents by Mahnik et al. (2007), at concentrations ranging from $<0.26$ to $1.35 \mu \mathrm{g} \mathrm{L}^{-1}$. ET is detectable in hospital effluents at concentrations of 6-380 $\mathrm{ng} \mathrm{L}^{-1}$ (Yin et al., 2010; Kosjek and Heath, 2011), and to the best of our knowledge nothing is known about kinase inhibitors. Nevertheless, the persistent release of these drugs might lead to long-term toxicity at lower concentrations than acute effects, and chronic endpoints might be the most relevant and important parameters for evaluating the real ecological risk (Crane et al., 2006).

\subsection{Chronic toxicity results}

The chronic toxicity data for the six cytostatics, expressed as $\mathrm{EC}_{50}, \mathrm{EC}_{20}$, and $\mathrm{EC}_{10}$ values in $\mu \mathrm{g} \mathrm{\textrm {L } ^ { - 1 }}$, is reported in Table 3. Among the organisms tested, $D$. magna and $C$. dubia were the most sensitive whereas $B$. calyciflorus was not particularly affected by cytostatics. As expected, chronic toxicity occurred at lower concentrations than acute toxicity, and the lowest $\mathrm{EC}_{50}$ values were found for CisPt and 5-FU on both crustaceans and rotifers. In crustaceans, these drugs were toxic at concentrations in the order of units or dozen of $\mu \mathrm{g} \mathrm{L}^{-1}$ and their activity was two or three orders of magnitude less against rotifers. As reported in the chemical results, CisPt is quickly hydrolysed into different compounds, and its toxicity could be related to the newly formed stable mixture. ET and IM induced 50\% reproduction inhibition in crustaceans, in the order of hundreds of $\mu \mathrm{g} \mathrm{L}^{-1}$ while CAP showed the lowest chronic potential,

Table 2

$\mathrm{L}(\mathrm{E}) \mathrm{C} 50$ values in $\mathrm{mg} \mathrm{L}^{-1}$ for acute toxicity tests with $95 \%$ confidence range for the cytostatics tested.

\begin{tabular}{|c|c|c|c|c|}
\hline Compd & D. magna $48 \mathrm{~h}$ & C. dubia $24 \mathrm{~h}$ & B. calyciflorus $24 \mathrm{~h}$ & T. platyurus $24 \mathrm{~h}$ \\
\hline $5-\mathrm{FU}$ & $20.84(18.07-24.04)$ & $501(351-854)$ & N.E. up to 200 & $0.28(0.26-0.29)$ \\
\hline CAP & $224(118-404)$ & $1.23 \times 10^{3}\left(0.9 \times 10^{3}-1.6 \times 10^{3}\right)$ & N.E. up to 500 & $197.7(174.7-223.7)$ \\
\hline CisPt & $0.94(0.90-0.97)$ & $2.50(2.13-2.97)$ & $6.52(4.31-9.86)$ & $8.44(7.18-9.91)$ \\
\hline DOX & $2.14(1.55-2.46)$ & $5.18(4.44-6.04)$ & $12.69(10.25-16.57)$ & $0.31(0.12-0.83)$ \\
\hline ET & $25 \%$ at 120 & $16 \%$ at 120 & N.E. up to 120 & $74.85(56.36-99.40)$ \\
\hline IM & $11.97(9.37-15.45)$ & $31.92(27.61-36.98)$ & $3.82(3.63-4.04)$ & $43.27(31.39-59.65)$ \\
\hline
\end{tabular}

N.E. No Effect.

Table 3

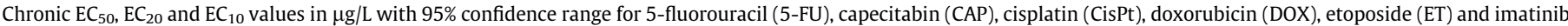
(IM).

\begin{tabular}{|c|c|c|c|c|c|c|c|c|c|}
\hline \multirow[t]{2}{*}{ Compd } & \multicolumn{3}{|l|}{ D. magna $21 \mathrm{~d}$} & \multicolumn{3}{|l|}{ C. dubia $7 \mathrm{~d}$} & \multicolumn{3}{|c|}{ B. calyciflorus $48 \mathrm{~h}$} \\
\hline & $\mathrm{EC}_{50}$ & $\mathrm{EC}_{20}$ & $\mathrm{EC}_{10}$ & $\mathrm{EC}_{50}$ & $\mathrm{EC}_{20}$ & $\mathrm{EC}_{10}$ & $\mathrm{EC}_{50}$ & $\mathrm{EC}_{20}$ & $\mathrm{EC}_{10}$ \\
\hline 5-FU & $\begin{array}{l}26.40(20.60- \\
33.90)\end{array}$ & $\begin{array}{l}8.77(5.81- \\
12.56)\end{array}$ & $4.60(2.75-7.82)$ & $\begin{array}{l}3.35(2.20- \\
5.09)\end{array}$ & $\begin{array}{l}1.07(0.55- \\
1.86)\end{array}$ & $\begin{array}{l}0.55(0.25- \\
1.23)\end{array}$ & $322(285-364)$ & $\begin{array}{l}181(149- \\
216)\end{array}$ & $\begin{array}{l}129(101- \\
167)\end{array}$ \\
\hline CAP & $\begin{array}{l}20.5 \times 10^{3} \\
\left(15.5 \times 10^{3}-\right. \\
\left.27.2 \times 10^{3}\right)\end{array}$ & $\begin{array}{l}5.8 \times 10^{3} \\
\left(3.7 \times 10^{3}-\right. \\
\left.8.7 \times 10^{3}\right)\end{array}$ & $\begin{array}{l}2.8 \times 10^{3}\left(1.6 \times 10^{3}-\right. \\
\left.5.0 \times 10^{3}\right)\end{array}$ & $\begin{array}{l}2.4 \times 10^{3} \\
\left(2.0 \times 10^{3}-\right. \\
\left.2.8 \times 10^{3}\right)\end{array}$ & $\begin{array}{l}0.9 \times 10^{3} \\
\left(0.6 \times 10^{3}-\right. \\
\left.1.1 \times 10^{3}\right)\end{array}$ & $\begin{array}{l}0.5 \times 10^{3} \\
\left(0.3 \times 10^{3}-\right. \\
\left.0.7 \times 10^{3}\right)\end{array}$ & $\begin{array}{l}15.4 \times 10^{3} \\
\left(11.3 \times 10^{3}-\right. \\
\left.21.1 \times 10^{3}\right)\end{array}$ & $\begin{array}{l}5.8 \times 10^{3} \\
\left(3.5 \times 10^{3}-\right. \\
\left.8.9 \times 10^{3}\right)\end{array}$ & $\begin{array}{l}3.3 \times 10^{3} \\
\left(0.1 \times 10^{3}-\right. \\
\left.6.2 \times 10^{3}\right)\end{array}$ \\
\hline CisPt & $\begin{array}{l}1.63(1.23- \\
2.18)\end{array}$ & $\begin{array}{l}0.49(0.31- \\
0.74)\end{array}$ & $0.25(0.14-0.45)$ & $\begin{array}{l}16.83(12.53- \\
22.65)\end{array}$ & $\begin{array}{l}4.03(2.49- \\
6.16)\end{array}$ & $\begin{array}{l}1.75(0.95- \\
3.27)\end{array}$ & $440(283-728)$ & $182(92-308)$ & $108(11-233)$ \\
\hline DOX & - & - & - & - & - & - & $\begin{array}{l}7.7 \times 10^{3} \\
\left(5.9 \times 10^{3}-\right. \\
\left.9.9 \times 10^{3}\right)\end{array}$ & $\begin{array}{l}6.2 \times 10^{3} \\
\left(4.8 \times 10^{3}-\right. \\
\left.8.1 \times 10^{3}\right)\end{array}$ & $\begin{array}{l}5.5 \times 10^{3} \\
\left(4.2 \times 10^{3}-\right. \\
\left.7.7 \times 10^{3}\right)\end{array}$ \\
\hline ET & 239 (181-299) & $137(90-190)$ & $98(61-161)$ & $\begin{array}{l}204(152- \\
256)\end{array}$ & $127(89-177)$ & $96(65-153)$ & $\begin{array}{l}3.7 \times 10^{3} \\
\left(2.7 \times 10^{3}-\right. \\
\left.5.3 \times 10^{3}\right)\end{array}$ & $\begin{array}{l}1.7 \times 10^{3} \\
\left(1.0 \times 10^{3}-\right. \\
\left.2.5 \times 10^{3}\right)\end{array}$ & $\begin{array}{l}1.0 \times 10^{3} \\
\left(0.3 \times 10^{3}-\right. \\
\left.1.9 \times 10^{3}\right)\end{array}$ \\
\hline IM & $308(147-872)$ & $\begin{array}{l}31.62(8.57- \\
84.33)\end{array}$ & $8.34(0.55-37.24)$ & $115(63-209)$ & $\begin{array}{l}3.0(0.99- \\
9.30)\end{array}$ & $\begin{array}{l}0.43(0.16- \\
2.04)\end{array}$ & $740(550-980)$ & $\begin{array}{l}260(150- \\
400)\end{array}$ & $140(70-270)$ \\
\hline
\end{tabular}

-Not determined. 
Table 4

Chronic NOEC and LOEC values in $\mu \mathrm{g} / \mathrm{L}$ of the cytostatics (Dunnett's test).

\begin{tabular}{|c|c|c|c|c|c|c|}
\hline \multirow[t]{2}{*}{ Compd } & \multicolumn{2}{|c|}{ D. magna $21 \mathrm{~d}$} & \multicolumn{2}{|c|}{ C. dubia $7 \mathrm{~d}$} & \multicolumn{2}{|c|}{ B. calyciflorus $48 \mathrm{~h}$} \\
\hline & NOEC & LOEC & NOEC & LOEC & NOEC & LOEC \\
\hline 5-FU & 2.06 & 6.17 & 2.22 & 6.67 & 125 & 250 \\
\hline CAP & 1900 & 6100 & 600 & 1900 & 3120 & 6250 \\
\hline CisPt & 1 & 3 & 4.57 & 14.65 & 250 & 500 \\
\hline DOX & - & - & - & - & 5000 & 10000 \\
\hline ET & 111.1 & 333.3 & 97.6 & 312.5 & 2500 & 5000 \\
\hline IM & 2.98 & 9.54 & 0.27 & 0.87 & 70 & 150 \\
\hline
\end{tabular}

-Not determinable.

with $\mathrm{EC}_{50}$ values in the order of $\mathrm{mg} \mathrm{L}^{-1}$. Since DOX is stable in the dark but degraded at the light, as shown by chemical analysis, chronic toxicity tests were not performed on D. magna and C. dubia. For this drug, the only chronic result was obtained for the rotifer because the test is performed in the dark and the $\mathrm{EC}_{50}$ value was slightly different from the acute value. From an environmental point of view, the photodegradability of DOX could represent a lower environmental risk, but further research is needed to evaluate the possible toxicity of photoderivatives. The similar toxicological sensitivities of $D$. magna and $C$. dubia are correlated to their similar taxonomy and the knowledge of the potential effects of drugs on these crustaceans is important for the ecosystem because they are a food source for amphibians, fish, and other organisms of the aquatic chain. For this reason, the chronic effects on D. magna over $21 \mathrm{~d}$ of exposure are required by the European Medical Agency (EMEA) for the further risk evaluation. Nevertheless $C$. dubia, which is largely used in North America, may be considered a suitable surrogate for $D$. magna, providing comparable data in one-third the experimental time (Constantine and Huggett, 2010). Because $C$. dubia and B. calyciflorus are not frequently used, no data about cytostatics is yet available on these organisms.

In addition to $\mathrm{EC}_{50}$ values, also $\mathrm{EC}_{20}$ and $\mathrm{EC}_{10}$ values for chronic toxicity are reported in Table 3 . These estimates could be useful to understand the slope in the low region of the concentration/effect curves and preferred in the environmental risk assessment instead of NOEC and LOEC. These latter are not measures of precision being based on the operator decisions for the chosen concentrations and their spacing (Fox, 2008). However, NOEC and LOEC are still the most frequently used measures for chronic toxicity in the low effect region; they are reported in Table 4.

Straub (2009) calculated the NOEC value for 5-FU according to OECD 211 and reported that it was $<10 \mu \mathrm{g} \mathrm{L}^{-1}$, representing the lowest nominal concentration tested. Zounkova et al. (2010) reported a 5-FU EC 50 value for D. magna of $100 \mu \mathrm{g} \mathrm{L}^{-1}$ calculated without confidence limits, approximately one-fold higher than the value shown in Table $3\left(26.40 \mu \mathrm{g} \mathrm{L}^{-1}\right)$. This difference may be due to the use of a broad concentration range (1:10 dilutions), which was probably not appropriate for defining the $\mathrm{EC}_{\mathrm{x}}$ with confidence limits since the OECD 211 relates that test concentrations may be arranged in a geometric series with a separation factor not exceeding 3.2. No chronic data is available in the literature except for the alga P. subcapitata reported by Zounkova et al. (2007). For this organism, CisPt and 5-FU exhibited the greatest toxic effects even if at concentrations in the order of $\mathrm{mg} \mathrm{L}^{-1}$; the chronic effect of DOX was similar to that found in our study for the rotifer. Straub (2009) reported a CAP EC $\mathrm{E}_{50}$ for algal growth inhibition of $2 \mathrm{mg} \mathrm{L}^{-1}$, which is similar to the effect shown in our study for $C$. dubia (2.4 $\mathrm{mg} \mathrm{L}^{-1}$ ) and one order of magnitude lower than D. magna and rotifers.

The dose-response curves with the respective error bars are summarized in Fig. 3. The curves clearly show an evident doseresponse effect for all drugs tested underlining the different responses of organisms to cytostatic concentration increasing. In
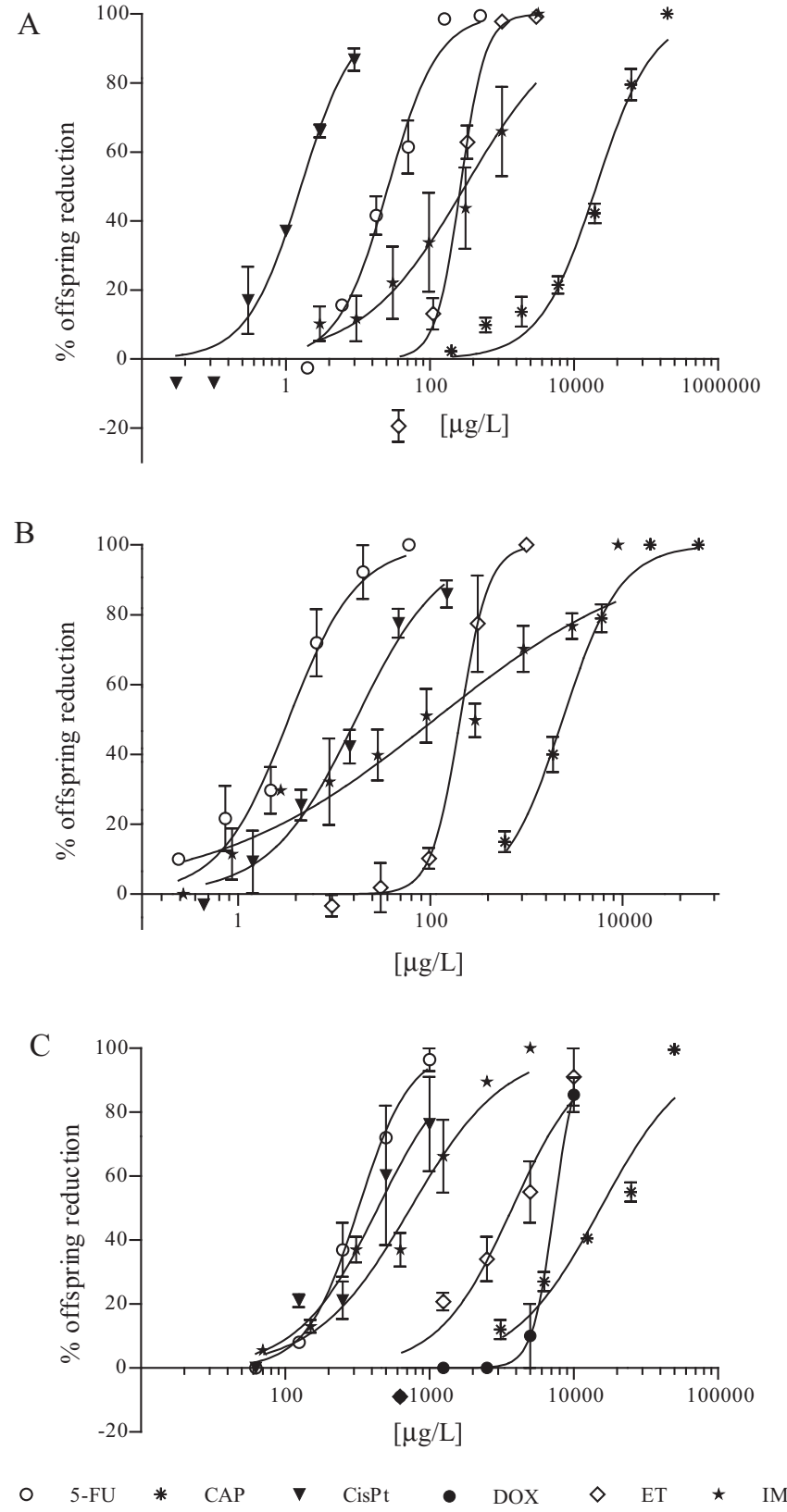

Fig. 3. Comparison of the concentration/effect curves of 5-fluorouracil (5-FU), capecitabine (CAP), cisplatin (CisPt), doxorubicin (DOX), etoposide (ET), and imatinib (IM) on D. magna (A), C. dubia (B), and B. calyciflorus (C). Bars indicate standard errors.

contrast to other drugs that have shown a rapid increase in concentration/effect relationship, the trend of IM was different with an evident response at only the highest concentrations.

In Table 5 the acute/chronic ratios (ACRs) are shown. As reported by Brausch et al. (2012), this ratio can provide a useful tool related to different modes of action of xenobiotics for multiple endpoints. The highest ACR values were found for 5-FU, which ranged from 789 for $D$. magna to $\approx 1.5 \times 10^{5}$ for $C$. dubia, showing an effect on a specific pathway, such as reproduction. The rotifer had the lowest ACR values.

Comparing our chronic results to the Predicted Environmental Concentration (PEC) values, refined by excretion rates, estimated by Besse et al. (2012), a potential risk of the cytostatics investigated may be considered. The 5-FU PEC was $7.91 \mathrm{ng} \mathrm{L}^{-1}$ and IM PEC was $4.99 \mathrm{ng} \mathrm{L}^{-1}$ (Table 1), two orders of magnitude lower than 
Table 5

Comparison of acute to chronic ratios (ACR) on different aquatic organisms for each cytostatic.

\begin{tabular}{llll}
\hline Compd. & D. magna & C. dubia & B. calyciflorus \\
\hline 5-FU & 789 & $1.5 \times 10^{5}$ & - \\
CAP & 11 & 493 & - \\
CisPt & 588 & 147 & 18 \\
DOX & - & - & 2 \\
ET & - & - & - \\
IM & 39 & 277 & 5
\end{tabular}

-Not determined because $\mathrm{EC}_{50}$ values for acute or chronic tests are not available as reported in the text.

the $C$. dubia $\mathrm{EC}_{10}$ (Table 3 ) indicating a possible damage for the aquatic ecosystem due to their increasing consumption and continuous release. DOX and ET exhibited a refined PEC value one order of magnitude less than 5-FU and IM, indicating a lower environmental concern.

\section{Conclusion}

The chronic ecotoxicological properties evaluated in the present study, the contrasting literature data on biodegradability in the environment, the high consumption amounts and the knowledge of human metabolism of 5-FU do not allow us to exclude a risk at long-term exposure for this cytostatic. As the occurrence data and the fate of CisPt are still lacking despite its successfully use in anticancer therapy, also in this case, our results cannot exclude harm for the environment. The lacking of both consumption and environmental fate data of IM do not let us to have a clear profile of its level of risk, while it seems that ET, DOX and especially CAP should be of less environmental concern considering their significant effects at almost high concentrations. Further research will be needed not only to investigate the effects of single compounds, but also those of derivatives obtained by biotic and abiotic transformations that occur in the environment. Furthermore, cytostatics are metabolized in the human body, leading to the formation of compounds whose degradation and environmental behavior are unknown. Importantly, in real water samples, single cytostatics act in mixtures with other cytostatics, metabolites, transformation products, and other pollutants with possible synergistic/antagonistic effects.

\section{Acknowledgements}

This work was financially supported by the EU through the EU FP7 project CytoThreat (Fate and effects of cytostatic pharmaceuticals in the environment and the identification of biomarkers for an improved risk assessment on environmental exposure. Grant agreement no. 265264).

\section{Appendix A. Supplementary material}

Supplementary data associated with this article can be found, in the online version, at http://dx.doi.org/10.1016/j.chemosphere. 2014.01.013.

\section{References}

ASTM E 1440-91, 2004. Standard guide for acute toxicity with the rotifer Brachionus. American Society for Testing and Materials. Philadelphia PA, USA reapproved.

Baek, I.H., Chae, JW. Chae, H.J., Kwon, K.I, 2010. Development and Validation of Robust LC-MS/MS Method for the Simultaneous Quantification of Doxifluridine and its Two Metabolites in Beagle Dog Plasma. Bull. Korean Chem. Soc. 31 (8), 2235-2241.

Besse, J.P., Latour, J.F., Garric, J., 2012. Anticancer drugs in surface waters: what can we say about the occurrence and environmental significance of cytotoxic, cytostatic and endocrine therapy drugs? Environ. Int. 39, 73-86.
Brausch, J.M., Connors, K.A., Brooks, B.W., Rand, G.M., 2012. Human pharmaceuticals in the aquatic environment: a review of recent toxicological studies and considerations for toxicity testing. Rev. Environ. Contam. Toxicol. $218,1-99$.

Blume-Jensen, P., Hunter, T., 2001. Oncogenic kinase signaling. Nature 411, 355365.

Catastini, C., Mullot, J.-U., Boukari, S., Mazellier, P., Levi, Y., Cervantes, P., Ormsby, J.N., 2008. Assessment of antineoplastic drugs in effluents of two hospitals | [Identification de molecules anticancéreuses dans les effluents hospitaliers]. J. Eur. Hydrol. 39 (2), 171-180.

Constantine, L.A., Huggett, D.B., 2010. A comparison of the chronic effects of human pharmaceuticals on two cladocerans, Daphnia magna and Ceriodaphnia dubia. Chemosphere 80, 1069-1074.

Crane, M., Watts, C., Boucard, T., 2006. Chronic aquatic environmental risks from exposure to human pharmaceuticals. Sci. Total. Environ. 367, 23-41.

Fox, D.R., 2008. NECs, NOECs and the ECX, Australas. J. Ecotoxicol. 14, 7-9.

Hartmann, A., Alder, A.C., Koller, T., Widmer, R.M., 1998. Identification of fluoroquinolone antibiotics as the main source of umuC genotoxicity in native hospital wastewater. Environ. Toxicol. Chem. 17, 377-382.

International Agency on the Research on Cancer. Agents classified by the IARC monographs. <http://monographs.iarc.fr/ENG/Classification/>. (accessed 10.04.13).

ISO 6341,1996 . Water quality-determination of the inhibition of the mobility of Daphnia magna Straus (Cladocera, Crustacea)-Acute toxicity test. International Organization for Standardization, Geneva, Switzerland.

ISO 10706, 2000. Water quality-determination of long term toxicity of substances to Daphnia magna Straus (Cladocera, Crustacea). International Organization for Standardization, Geneva, Switzerland.

ISO 14380, 2011. Water quality-Determination of the acute toxicity to Thamnocephalus platyurus (Crustacea, Anostraca). International Organization for Standardization, Geneva, Switzerland.

ISO 20665, 2008. Water quality-determination of chronic toxicity to Ceriodaphnia dubia in 7 days-population growth inhibition test. International Organization for Standardization, Geneva, Switzerland.

ISO 20666, 2008. Water quality-determination of chronic toxicity to Brachionus calyciflorus in $48 \mathrm{~h}$-population growth inhibition test.: International Organization for Standardization, Geneva, Switzerland.

Johnson, A.C., Jürgens, M.D., Williams, R.J., Kümmerer, K., Kortenkamp, A., Sumpter, J.P., 2008. Do cytotoxic chemotheraphy drugs discharged into rivers pose a risk to the environment and human health? An overview and UK case study. J. Hydrol. 348, 167-175.

Kartalou, M., Essigmann, J.M., 2001. Recognition of cisplatin adducts by cellular proteins. Mutat. Res. 478, 1-21.

Kosjek, T., Heath, E., 2011. Occurrence, fate and determination of cytostatic pharmaceuticals in the environment. Trends Anal. Chem. 30 (7), 1065-1087.

Kosjek, T., Perko, S., Žigon, D., Heath, E., 2013. Fluorouracil in the environment: analysis, occurrence, degradation and transformation. J. Chromatogr. A. 1290, $62-72$.

Kovalova, L., McArdell, C.S., Hollender, J., 2009. Challenge of high polarity and low concentrations in analysis of cytostatics and metabolites in wastewater by hydrophilic interaction chromatography/tandem mass spectrometry. J. Chromatogr. A 1216, 1100-1108.

Lenz, K., Mahnik, S.N., Weissenbacher, N., Mader, R.M., Krenn, P., Hann, S., Koellensperger, G., Uhl, M., Knasmueller, S., Ferk, F., Bursh, W., Fuerhacker, M., 2007. Monitoring, removal and risk assessment of cytostatic drugs in hospital wastewater. Water Sci. Technol. 56 (12), 141-149.

Mahnik, S.N., Lenz, K., Weissenbacher, N., Mader, R.M., Fuerhacker, M., 2007. Fate of 5-fluorouracil, doxorubicin, epirubicin, and daunorubicin in hospital wastewater and their elimination by activated sludge and treatment in a membrane-bio-reactor system. Chemosphere 65 (1), 30-37.

Mahnik, S.N., Rizovski, B., Fürhacker, M., Mader, R.M., 2004. Determination of 5fluorouracil in hospital effluents. Anal. Bioanal. Chem. 380, 31-35.

Mahnik, S.N., Rizovski, B., Fuerhacker, M., Mader, R.M., 2006. Development of an analytical method for the determination of anthracyclines in hospital effluents. Chemosphere 65 (8), 1419-1425.

Martin, J., Camacho-Munoz, D., Santos, J.L., Aparicio, I., Alonso, E., 2011. Simultaneous determination of a selected group of cytostatic drugs in water using high-performance liquid chromatography-triple-quadrupole mass spectrometry. J. Sep. Sci. 34, 3166-3177.

Miller, S.E., House, D.A., 1989a. The hydrolysis products of cisdiamminedichloroplatinum(II).I. The kinetics of formation and anation of the cis-diammine(aqua)chloroplatinum(II) cation in acidic aqueous solution. Inorganica Chim Acta. 161, 131-137.

Miller, S.E., House, D.A., 1989b. The hydrolysis products of cisdichlodiammineplatinum(II).2. The kinetics of formation and anation of the cis-diammine(aqua)chloroplatinum(II) cation. Inorganica Chim Acta. 166, 189197

Miller, S.E., House, D.A., 1990. The hydrolysis products of cisdichlorodiammineplatinum(II).3. Hydrolysis kinetics at physiological pH. Inorganica Chim Acta. 173, 53-60.

Minotti, G., Menna, P., Salvatorelli, E., Cairo, G., Gianni, L., 2004. Anthracyclines: molecular advances and pharmacologic developments in antitumor activity and cardiotoxicity. Pharmacol. Rev. 56 (2), 185-229.

Mompelat, S., Le Bot, B., Thomas, O., 2009. Occurrence and fate of pharmaceutical products and by-products, from resource to drinking water. Environ. Int. 35, 803-814. 
Nawara, K., Krysinski, P., Blanchard, G.J., 2012. Photoinduced reactivity of doxorubicin: catalysis and degradation. J. Phys. Chem. A. 116 (17), 4330-4337.

Negreira, N., Mastroianni, N., López de Alda, M., Barceló, D., 2013. Multianalyte determination of 24 cytostatics and metabolites by liquid chromatographyelectrospray-tandem mass spectrometry and study of their stability and optimum storage conditions in aqueous solution. Talanta 116, 290-299.

OECD 202, 2004. Daphnia sp., acute immobilization test. Organization for Economic Co-operation and Development, Paris.

OECD 211, 2008. Daphnia magna reproduction test. Organization for Economic Cooperation and Development, Paris.

Shi, S., Yao, W., Xu, J., Long, J., Liu, C., Yu, X., 2012. Combinational therapy: new hope for pancreatic cancer? Cancer Lett. 317 (2), 127-135.

Straub, J.O., 2009. Combined environmental risk assessment for 5-fluorouracil and capecitabine in Europe. Integr. Environ. Assess. Manage. 6 (1), 540-566.

Suhail, N., Bilal, N., Khan, H.Y., Hasan, S., Sharma, S., Khan, F., Mansoor, T., Banu, N. 2012. Effect of vitamins $C$ and $E$ on antioxidant status of breast-cancer patients undergoing chemotherapy. J. Clin. Pharm. Ther. 37, 22-26.

Tarczynska, M., Nalecz-Jawecki, G., Romanowska-Duda, Z., Sawicki, J., Beattie, K., Codd, G., Zalewski, M., 2001. Tests for the toxicity assessment of cyanobacterial bloom samples. Environ. Toxicol. 16, 383-390.
Tauxe-Wuersch, A., De Alencastro, L.F., Grandjean, D., Tarradellas, J., 2006. Trace determination of tamoxifen and 5-fluorouracil in hospital and urban wastwaters. Int. J. Environ. Anal. Chem. 86, 473-485.

US EPA, 1993. Methods for measuring the acute toxicity of effluents and receiving waters to freshwater and marine organisms, fourth ed. EPA-600-4-90. Washington DC: US Environmental Protection Agency.

Xie, H., 2012. Occurrence, ecotoxicology, and treatment of anticancer agents as water contaminants. J. Environ. Anal. Toxicol., S:2.

Yin, J., Shao, B., Zhang, J., Li, K., 2010. A preliminary study on the occurrence of cytostatic drugs in hospital effluents in Beijing. China. Bull. Environ. Contam. Toxicol. 84 (1), 39-45.

Zaltauskaite, J., Brazaityte, V., 2013. Assessment of the effect of sulfonylureas herbicide amidosulforum application on target and non-target organisms. Fresenius Environ. Bull. 22 (7a), 1977-1982.

Zounkova, R., Kovalova, L., Blaha, L., Dott, W., 2010. Ecotoxicity and genotoxicity assessment of cytotoxic antineoplastic drugs and their metabolites. Chemosphere 81, 253-260.

Zounkova, R., Odráška, P., Doležalová, L., Hilscherová, K., Maršálek, B., Bláha, L. 2007. Ecotoxicity and genotoxicity assessment of cytostatic pharmaceuticals. Environ. Toxicol. Chem. 26 (10), 2208-2214. 